\title{
Effect of Buccal Corridors Width on Smile Quality and Esthetics
}

\author{
Hina Siddiqui ${ }^{1}$ \\ Sadia Rizwan ${ }^{2}$ \\ Syed Shah Faisal ${ }^{3}$ \\ Syed Sheeraz Hussain ${ }^{4}$
}

BDS

BDS, FCPS

BDS, FCPS

BDS, DCPS, MCPS, FCPS

OBJECTIVE: To assess the perception of buccal corridor width on smile esthetics by Orthodontic residents, General dentists and Laypersons

METHODOLOGY: A smile photograph was taken of an adult female. The image was modified to obtain five different buccal corridor widths and were assessed by different evaluators grouped into general dentist, orthodontic resident and laypersons who rated the attractiveness of each smile by means of a visual analog scale (VAS). Sample size was 97 participants to rate the picture. Non-probability purposive sampling was done The data was analyzed and mean and SD were calculated for the scores of rating. ANOVA and Tukey's post hoc test was applied to compare the different ratings of buccal corridors in three groups. The data of this cross sectional study was collected from general population belonging to different communities, general dentists and orthodontic residents of different dental colleges of Karachi, Pakistan from August 2019 to March 2020.

RESULTS: There were 97 participants who responded to the images. Highest scores were obtained for Image 1 having buccal corridor width ratio of $16 \%$ followed by image no. 3 having buccal corridor width ratio of $10 \%$ and lowest scores were obtained for Image no. 6 having least buccal corridor widths ratio that is $34 \%$ followed by image no 5 having $26 \%$ buccal corridor widths. Among the groups of participants, the highest scores were given by laypersons for all images. Significant differences were observed between evaluation of groups of Orthodontic resident and layperson in most images.

CONCLUSION: There was a remarkable influence of buccal corridor width on smile esthetics, with the $16 \%$ ratio group being rated as the most attractive by all three groups.

KEYWORDS: Buccal corridors, Smile, esthetics, Attractiveness

HOW TO CITE: Siddiqui H, Rizwan S, Faisal SS, Hussain SS. EFfect of buccal corridors width on smile quality and esthetics. J Pak Dent Assoc 2021;30(3):204-208.

DOI: https://doi.org/10.25301/JPDA.303.204

Received: 13 November 2020, Accepted: 27 April 2021

\section{INTRODUCTION}

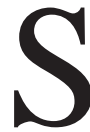
mile is one of the most unique features describing the personality. In humans, it is naturally a manifestation signifying delight, cheerfulness, and enjoyment. An attractive smile increases self-assurance, self-worth and confidence. ${ }^{1}$ It is the utmost means by which individuals convey their feelings. It is defined as 'a transformation of face expression encompassing eyes enhancement, uphill bowing of the curls of lips with no sound and reduced alteration of the muscles than in laugh

1. FCPS II Trainee, Department of Orthodontics, Karachi Medical \& Dental College,

2. Assistant Professor, Department of Orthodontics, Dr. Ishrat-ul-Ibad Khan Institute of Oral Health Sciences.

3. Vice Principal, College of Dentistry, Professor, Department of Orthodontics, Karachi Medical \& Dental College.

4. Principal, College of Dentistry, Professor and HOD, Department of Orthodontics, Karachi Medical and Dental College.

Corresponding author: “Dr. Hina Siddiqui” < hinasiddiqui616@gmail.com > which possibly will precise enjoyment, amusement, care, love, warmth, merriment, sarcasm, or any of many different sentiments. ${ }^{2}$ Its impact, though, is not linked solely to the individual dental beauty. ${ }^{3}$ The esthetics remain an imprint in the intellect encouraged by its specific insight; hence, the learning of individual attractiveness has ensued in all beliefs throughout past and beauty employs a personal idea. It is a noteworthy part of one's personality and the awareness of the individual and in addition it is imperative in the evaluation that others have of our expression and character. ${ }^{4}$

There are four key features of aesthetic perception of smile: facial, gingival, micro and macro-aesthetics. Smile Esthetics depends upon teeth as well as soft tissue. ${ }^{5}$ Smile analysis includes valuation of smile arc, smile line, tooth and gingival display, presence or absence of buccal corridor widths, facial and dental midlines, proportions of tooth, gingival heights and shade of tooth. ${ }^{6}$ One of potential smile feature is buccal corridors. ${ }^{7}$ However some data on the perfect size of buccal corridors is available in the literature, 
maximum of it is stranded in views of clinicians, although the researches that endeavored this issue produced controversial assumptions. ${ }^{8}$ Numerous researches exhibited that broad smiles with reduced negative spaces are cherished and considered more eye-catching. ${ }^{9}$ Lately, extremely wide BCs are denoted by many orthodontic consultants as a "negative space," and must be omitted by expansion of the upper arch. It is predictable in the literature of prosthodontics that one of the configurations of an unnatural denture like smile is the absence of buccal corridors. ${ }^{10}$ It might not an easy task to recognize the problem with the smile esthetics because of the variations in opinions among orthodontists and laypersons. ${ }^{11}$ A welcoming and eye catching smile is deliberated as a crucial benchmark by many patients, describing the accomplishment of treatment, even though the attainment of a proportionate smile can be perplexing due to the bias of assessment. It is significant to assess the consequence of the dentition on the smile. A lack of data has prohibited an acceptable considerate of the appealingly proportionate widths of the smile. Consequently, it is essential to generate common guidelines to help clinicians in improving smile esthetics with sufficient treatment objectives fulfillment. $^{12}$

Visual analog scale appears to be reliable for evaluation of smile esthetics. ${ }^{13}$ In present practice of dentistry, an enormous number of patients are demanding a highly aesthetic treatment result. ${ }^{14}$ Buccal Corridors can be best assessed on the Frontal Smile Photograph which is now an essential component for Orthodontic Diagnosis \& Treatment Planning. Presence or absence of buccal corridors has been best evaluated by analyzing Buccal Corridor width. Buccal corridors were defined by Frush and Fisher as the space from the buccal surface of visible posterior teeth and the corners of lips, when the patient is smiling. ${ }^{3}$

In a study conducted by Bilal $\mathrm{R}$ buccal corridors was the 5th most desired feature amid orthodontists. ${ }^{11}$ In a study conducted by Zaib $\mathrm{F}$ et al. prefer smiles with minimum visible buccal corridors, where male orthodontists rated $20 \%$ pictures as acceptable and female orthodontist judges rated 23\% pictures as acceptable. ${ }^{15}$ Abdullah Alper Öz concluded that both orthodontists and oral surgeons gave ratings of $12 \% \mathrm{BC}$ width as the most appealing, whereas group of prosthodontic consultants and laypersons accepted a rating of width of buccal corridors being $0 \%$ as the most beautifully agreeable. ${ }^{10}$ Lay perceptions of smile esthetics are imperative to better understand the treatment objectives from perspective of a patient. However, it is clear that laypeople can recognize numerous factors which affect smile esthetics. Perception is defined as a reasoning process involving understanding of a stimulus and recognition of the object generating a sensation. ${ }^{16}$
This study will help us understand the opinion and perception of laypersons, which often are not given the due importance in the treatment planning. Also it will help orthodontic residents realize that they should not impose their own perception of smile and esthetics on their patients. This individual assessment is an effort to validate and expand on earlier studies of smile acceptability and deliver esthetic ideals.

\section{METHODOLOGY}

It was a questionnaire based cross sectional study. This data of this cross sectional study was collected from general population belonging to different communities, general dentists and orthodontic residents of different dental colleges of Karachi, Pakistan. Sample size was 97 participants to rate the picture which is calculated by taking anticipated population proportion (P) as $20 \%$ acceptable, margin of error $8 \%$ and $95 \%$ Confidence interval. Non-probability purposive sampling was done. Participants, including both males and females of age range 24-34 years were recruited in the study. Three groups of participating evaluators were formed. The first group consisted of 32 Orthodontic residents from different institutes in Karachi, the second group comprised of 32 general dentists practicing in different dental hospitals in Karachi and third group included 33 laypersons. Orthodontic residents having minimum 2 years of experience in the field were selected, General dentist having minimum 2 years of experience and laypersons were graduates in any field other than dentistry. People who do not give consent to participate were excluded.

The data was collected after taking approval from ethical review board in KMDC (Ref. no 025/18) by taking frontal photograph of 1 female individual of age 23 years by using DSLR camera; Canon 700d. Frontal smile view photograph with the head in naturally relaxed position of the subject will be taken and only close up smile image was framed. Original photograph had ratio of buccal corridor width of $16 \%$. The photograph was modified by software of adobe photoshop 7.0 to obtain 5 different buccal corridor width ratios that is; $8 \%, 10 \%, 22 \%, 26 \%$ and 34\%. (Figure no. 1) Informed consent was taken from the photographed female and all the participating evaluators. All images were printed and were given to participants to rate the facial attractiveness from 1 to 10 of each image by using visual analogue scale keeping 1 as least attractive and 10 as most attractive in a predesigned proforma. The current study altered only the buccal corridor ratio for smiles which eliminated the possibility of other confounding aesthetic variables influencing perceptions.

The space perceived between the facial surface of the 
Figure 1: Modifications for buccal corridor width
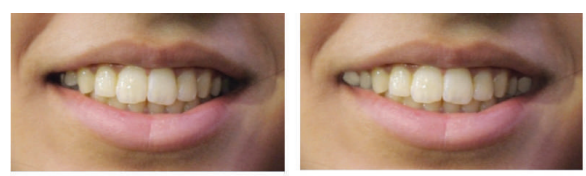
$2(8 \% \mathrm{BCW})$ 1 (Original image $16 \%$ BCW)

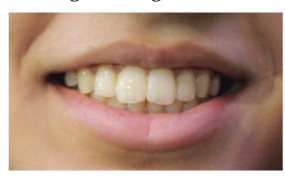

$4(22 \% \mathrm{BCW})$

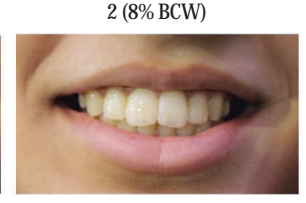

$5(26 \% \mathrm{BCW})$

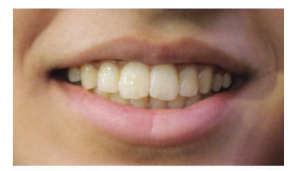

$3(10 \% \mathrm{BCW})$

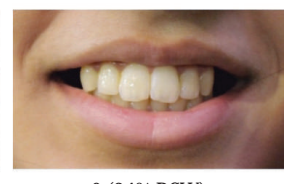

$6(34 \% \mathrm{BCW})$

Table 2: Statistical differences in evaluation of smiles by participants

teeth in posterior region and the corners of the lips when the patient smiles is known as the buccal corridor. The measurements are taken from the mesial line angle of maxillary first premolar to the inferior part of the commissure of the lip. ${ }^{17}$

The data was statistically analyzed using SPSS 23. Mean and SD were taken for scores given by the participating evaluators for all the images. Differences between ratings by groups of participants were analyzed by applying one-way ANOVA and Tukey's post hoc test taking p-value less than 0.05 as significant.

\section{RESULTS}

Table I illustrated the means and standard deviations for the ratings obtained from evaluators for individual groups., the maximum ratings were attained for Image 1 having buccal corridor width ratio of $16 \%$ followed by

Table 1: Descriptive statistics: mean smile ratings on visual analog scale

\begin{tabular}{|l|l|l|l|l|}
\hline $\begin{array}{l}\text { IMAGE. } \\
\text { NO. }\end{array}$ & $\begin{array}{l}\text { BCW } \\
\text { RATIO } \%\end{array}$ & $\begin{array}{l}\text { ORTHODONTIC RESIDENT } \\
\text { N=32 }\end{array}$ & $\begin{array}{l}\text { GENERAL DENTIST } \\
\text { LAYPERSON }\end{array}$ & $\begin{array}{l}\text { N=32 } \\
\text { N=33 }\end{array}$ \\
\hline 1 & $16 \%$ & $8.50 \pm 1.191$ & $7.63 \pm 1.845$ & $8.45 \pm 1.175$ \\
\hline 2 & $8 \%$ & $4.44 \pm 1.831$ & $4.78 \pm 2.893$ & $6.45 \pm 2.386$ \\
\hline 3 & $10 \%$ & $6.34 \pm 1.771$ & $6.25 \pm 1.934$ & $6.45 \pm 2.152$ \\
\hline 4 & $22 \%$ & $5.66 \pm 2.104$ & $6.34 \pm 1.807$ & $6.97 \pm 1.741$ \\
\hline 5 & $26 \%$ & $3.66 \pm 1.638$ & $4.94 \pm 2.409$ & $5.64 \pm 1.782$ \\
\hline 6 & $34 \%$ & $2.22 \pm 1.362$ & $2.13 \pm 1.338$ & $3.42 \pm 2.136$ \\
\hline
\end{tabular}

image no 3 having buccal corridor width ratio of $10 \%$ and lowest scores are obtained for Image no. 6 having least buccal corridor widths ratio that is $34 \%$ followed by image no 5 having $26 \%$ buccal corridor widths. The highest scores are given by laypersons group for all the photographs.

Table II demonstrated the statistically significant differences among the groups of evaluators for the perception of smile attractiveness, mostly differences are observed between evaluation of groups of Orthodontic resident and layperson and are significant for Image no. 2,4,5 and 6. In image 5 and 6 where buccal corridor width was markedly

\begin{tabular}{|c|c|c|c|c|c|c|c|}
\hline \multirow[t]{2}{*}{$\underline{\text { IMAGE }}$} & \multirow[t]{2}{*}{$\underline{\mathrm{BCW} \%}$} & \multicolumn{2}{|c|}{$\begin{array}{l}\text { ORTHO RESIDENT/ } \\
\text { GEN. DENTIST }\end{array}$} & \multicolumn{2}{|l|}{$\begin{array}{l}\text { GEN. DENTIST/ } \\
\text { LAYPERSON }\end{array}$} & \multicolumn{2}{|c|}{$\begin{array}{l}\text { LAYPERSON/ } \\
\text { ORTHO RESIDENT }\end{array}$} \\
\hline & & Mean difference & $\underline{\text { Sig. }}$ & Mean difference & $\underline{\text { Sig. }}$. & Mean difference & $\underline{\text { Sig. }}$. \\
\hline 1. & $16 \%$ & $0.875^{*}$ & \begin{tabular}{|l|}
0.44 \\
\end{tabular} & \begin{tabular}{|l|l|}
-0.830 \\
\end{tabular} & 0.57 & \begin{tabular}{|l|}
-0.46 \\
\end{tabular} & 0.991 \\
\hline 2 & $8 \%$ & $\begin{array}{l}-0.344 \\
\end{array}$ & 0.836 & $-0.1673^{*}$ & 0.17 & $2.017^{*}$ & 0.003 \\
\hline 3 & $10 \%$ & 0.94 & 0.980 & -0.205 & 0.907 & \begin{tabular}{|l|}
0.111 \\
\end{tabular} & 0.972 \\
\hline 4 & $22 \%$ & $\begin{array}{l}-0.688 \\
\end{array}$ & 0.317 & -0.626 & 0.379 & $1.313^{*}$ & 0.17 \\
\hline 5 & $26 \%$ & $-1.281^{*}$ & 0.29 & \begin{tabular}{|l|}
-0.699 \\
\end{tabular} & 0.330 & $1.980^{*}$ & 0.000 \\
\hline 6 & $34 \%$ & 0.094 & 0.972 & \begin{tabular}{|l|c|} 
\\
\end{tabular} & 0.006 & $1.205^{*}$ & 0.012 \\
\hline
\end{tabular}

increased orthodontic residents differed significantly in ratings with laypersons.

\section{DISCUSSION}

Orthodontists used to widen the maxilla to relieve crowding, it is noteworthy to know how variations in the display of teeth while smiling affect facial attractiveness. In our study, the image having Buccal Corridor width ratio of $16 \%$ appeared to be most attractive among all images and the image having buccal corridor width ratio of $34 \%$ were rated to be least attractive followed by image having $26 \%$ buccal corridor width ratio which means all three evaluators groups preferred lesser buccal corridor widths. Image having reduced buccal corridor width $8 \%$ also received lower ratings by Orthodontic residents and general dentists whereas laypersons did not critically scored image having reduced buccal corridors. This study also showed that orthodontic residents analyzed pictures more critically as compared to laypersons having significant differences in four pictures. Overall scoring was greater by laypersons as compared to other two groups of evaluators.

In a comparable study, smiling pictures of female were used for assessment, Ioi et al. stated that orthodontic specialists and laypersons evaluated a buccal corridor width of $10 \%$ and $5 \%$, as the most appealingly attractive. Where as in our study less buccal corridors around $16 \%$ are most acceptable and least buccal corridors i.e.; 8\% received lower ratings, and smiles with buccal corridor width of $34 \%$ received much lower ratings from all three evaluator groups. ${ }^{18}$

Outcomes of our study are also in favor with findings of Moore et al, he used full face slides and changed the maxillary dentition to 5 widths. The results of their study also showed that wider smiles were preferred, as shown in our study. ${ }^{19}$ The findings of this study are consistent with that of Parekh et al., he found significantly reduced ratings for smiles having flat smile arcs and increased buccal corridors similar to our study. Our study also showed very low scores for increased buccal corridor space. ${ }^{20}$ Our study findings also supported results of Martin et al who also concluded that orthodontists 
and laypeople scored smiles having less buccal corridors as more attractive than those with increased buccal corridors. ${ }^{21}$ Our findings are also in agreement with those of Kokich et al, who stated that laypersons, dentists and orthodontists have different altitudes of recognition of variations in smile features and that laypersons were the most forgiving. ${ }^{22}$

However, in a study conducted by Roden-Johnson et al. declared that the extent of buccal corridor width was not an important aspect in the charm of smile. Though, significant dissimilarities were found in the approaches of this study when matched to the present research. ${ }^{10}$ Their study showed that the occurrence of buccal corridors does not influence smile esthetics. However, there are variations in how dentists, orthodontists, and laypeople scored smiles and in what arch form respective group desires. Ritter et al. examined the significance of different buccal corridor widths, but samples they used were unchanged smile pictures of the subjects ${ }^{10}$ which can lead to bias in ratings due to other smile features which affect the smile attractiveness. Furthermore, the number of inspectors are also reduced which affect the outcome of study. They found that buccal corridor width did not influence the attractiveness of smile. Contradicting to our study, McNamara et al. showed significant agreement in the decisions between laypersons and orthodontic specialists regarding perception of smile, whereas our findings demonstrated significant differences in four images between orthodontic resident and laypersons. ${ }^{23}$ A study by Husley proved that smile arc had greater scores and buccal corridors did not have any consequence on smile aesthetics which is contradicting to the present study. The disagreement might be due to different treatment groups taken for evaluation of buccal corridors widths. ${ }^{24} \mathrm{Al}$ Taki et al stated that orthodontists showed great precision in tolerating deviations in the smile arc and buccal corridors 25 which is similar to findings of our study showing more sensitive ratings made by orthodontic residents among all groups of evaluators.

\section{CONCLUSIONS}

1. All three groups of evaluators that is orthodontic residents, general dentists and laypersons preferred smiles having $16 \%$ buccal corridors width ratio.

2. There is no gender or age group difference in ratings given by evaluator groups.

3. Excessive buccal corridor widths i.e.; $34 \%$ and minimum buccal corridors widths i.e.; $8 \%$ both are rated to be least acceptable by all three evaluator groups.

4. Orthodontists and general dentists, shared more similarities than differences when evaluating smile esthetics in the present study.
5. Differences in ratings were observed among Orthodontic resident and layperson groups.

6. The layperson group were more forgiving in scoring smile related to buccal corridor width ratio than Orthodontic residents and general dentists.

\section{CONFLICT OF INTEREST}

None to declare

\section{REFERENCES}

1. Kar M, Muluk NB, Bafaqeeh SA, Cingi C. Is it possible to define the ideal lips? Acta Otorhinolaryngol Ital. 2018;38:67-72.

https://doi.org/10.14639/0392-100X-1511

2. Gaikwad S, Kaur H, Vaz AC, Singh B, Taneja L, Vinod KS, Verma P. Influence of Smile Arc and Buccal Corridors on Facial Attractiveness: A Cross-sectional Study. J Clin Diagnos Res.2016;10: ZC20-23 https://doi.org/10.7860/JCDR/2016/19013.8436

3. Frush JO, Fisher RD. The dynesthetic interpretation of the dentogenic concept. J Prosthet Dent;1958; 8:558-81

https://doi.org/10.1016/0022-3913(58)90043-X

4. Mora MG, Serna MEV, Ledesma AF; Perception of smile esthetics by dental specialists and patient; Revista Mexiacana de Orthodoncia 2015;3:13-21

https://doi.org/10.1016/j.rmo.2016.03.006

5. Memon W, Ghani A, Naz I, Jatoi NH, Ali A; Smile perception amongst orthodontists and laypersons; Pak Orthodontic J 2017;9: $56-60$

6. Elham SJ, Alhaija ES, Shamsi AN, Khateeb SA. Perceptions of Jordanian laypersons and dental professionals to altered smile aesthetics. Eur J Orthod 2011; 33:450-56

https://doi.org/10.1093/ejo/cjq100

7. Oliveira PLE, Motta A, Pithon M, Mucha Details of pleasing smiles. J.Int J Esthet Dent. 2018;13:494- 514.

8. Nimbalkar S, Oh YY, Mok RY, Tioh JY, Yew KJ, Patil PG.Smile attractiveness related to buccal corridor space in 3 different facial types: A perception of 3 ethnic groups of Malaysians. J Prosthet Dent. 2018;120:252-56.

https://doi.org/10.1016/j.prosdent.2017.10.021

9. Sadrhaghighi AH, Zarghami A, Sadrhaghighi S, Mohammadi A, Eskandarinezhad M. Esthetic preferences of laypersons of different cultures and races with regard to smile attractiveness.Ind J Dent Res. 2017;28:156-161

https://doi.org/10.4103/0970-9290.207795

10. Oz AA, Akdeniz BS, Canli E, Celik S. Differences among the perceptions of dental professionals and laypersons. Turk J Orthod 2017; 30:50-5.

https://doi.org/10.5152/TurkJOrthod.2017.17021 
11. Bilal R; a comparative analysis of smile perception between orthodontists and laypersons; Pak Dent J;2015;35;4:596-600

12. Zhang K, Huang L, Yang L, Xu L, Xue C, Xiang Z, Zhao M, Li S, Bai Y, Bai D. Effects of transverse relationships between maxillary arch, mouth, and face on smile esthetics. The Angle Orthodontist. 2016;86:135-41.

https://doi.org/10.2319/101514.1

13. Oliveira PL, Motta AF, Guerra CJ, Mucha JN. Comparison of two scales for evaluation of smile and dental attractiveness. Dent Press J Orthod 2015;20:42-8.

https://doi.org/10.1590/2176-9451.20.2.042-048.oar

14. Omar D, Duarte C. The application of parameters for comprehensive smile esthetics by digital smile design programs: A review of literature. Saudi Dent J. 2018; 30:7-12.

https://doi.org/10.1016/j.sdentj.2017.09.001

15. Zaib F, Hameed WU. Effect of buccal corridors width on smile aesthetics. Pak Ortho J; 2009:1-5.

16. Parrini S, Rossini G, Castroflorio T, Fortini A, Deregibus A, Debernardi C. Laypeople's perceptions of frontal smile esthetics: a systematic review. Am J Orthodo Dentofac Orthopedi. 2016;150: 740-50.

https://doi.org/10.1016/j.ajodo.2016.06.022

17. Kaur S. Gemstone of human personality: The smile. Int J Orthod Rehabil. 2018;9:72.7

https://doi.org/10.4103/ijor.ijor_43_17

18. Ioi H, Nakata S, Counts AL. Effects of buccal corridors on smile estheticsa in Japanese. Angle Orthod 2009; 79: 628-33.

https://doi.org/10.2319/080708-410.1
19. Moore T, Southard KA, Casko JS, Qian F, Southard TE. Buccal corridors and smile esthetics. Am J Orthod Dentofacial Orthop 2005;127:208-13.

https://doi.org/10.1016/j.ajodo.2003.11.027

20. Parekh S, Fields HW, Beck FM, Rosenstiel SF. The acceptability of variations in smile arc and buccal corridor space. Orthod Craniofac Res 2007;10:15-21.

https://doi.org/10.1111/j.1601-6343.2007.00378.x

21. Martin AJ, Buschang PH, Boley JC, Taylor RW, McKinney TW. The impact of buccal corridors on smile attractiveness. The European J Orthodontics. 2007;29:530-37. https://doi.org/10.1093/ejo/cjm063

22. Kokich VG. Esthetics: the orthodontic-periodontic restorative connection. Semin Orthod 1996;2:21-30.

https://doi.org/10.1016/S1073-8746(96)80036-3

23. McNamara L, McNamara JA, Jr., Ackerman MB, Baccetti T. Hard- and soft-tissue contributions to the esthetics of the posed smile in growing patients seeking orthodontic treatment. Am J Orthod Dentofacial Orthop 2008;133:491-9.

https://doi.org/10.1016/j.ajodo.2006.05.042

24. Hulsey CM. An esthetic evaluation of lip-teeth relationships present in the smile. Am J Orthod 1970; 57:132-44. https://doi.org/10.1016/0002-9416(70)90260-5

25. Al Taki A, Khalesi M, Shagmani M, Yahia I, Al Kaddah F. Perceptions of altered smile esthetics: A comparative evaluation in orthodontists, dentists, and laypersons. Int J Dentistry. 2016;Article ID 7815274.

https://doi.org/10.1155/2016/7815274 